\title{
Mobilization of Heavy Metals in Contaminated Soils induced by Bioaugmentation of Shewanella xiamenensis HM14
}

\author{
Buddhi Charana Walpola, KKIU Arunakumara, Jun-Seob Song ${ }^{1}$, Chan-Jung Lee ${ }^{2}$, and Min-Ho Yoon ${ }^{1 *}$ \\ Department of Crop Science, Faculty of Agriculture, University of Ruhuna, Kamburupitiya, Sri Lanka \\ ${ }^{I}$ Department of Bio-Environmental Chemistry, College of Agriculture and Life Sciences, \\ Chungnam National University, Daejeon, 305-764, Korea \\ ${ }^{2}$ Mushroom Research Division, National Institute of Horticultural \& Herbal Science, RDA, Eumseong 369-873, Korea
}

(Received: August 11 2014, Revised: August 13 2014, Accepted: August 24 2014)

\begin{abstract}
A bacterial strain with the potential ability to solubilize heavy metals was isolated from heavy metal contaminated soils collected from abandoned mines of Boryeong area in South Korea. The bacterial strain with the highest degree of metal resistance was shown to have close proximity with Shewanella xiamenensis FJ589031, according to 16S rRNA sequence analysis, and selected for investigating the mobilization of metals in soil or plant by the strain. The strain was found to be capable of solubilizing metals both in the absence and in the presence of metals $(\mathrm{Co}, \mathrm{Pb}$ and $\mathrm{Cd})$. Metal mobilization potential of the strain was assessed in a batch experiment and the results showed that inoculation could increase the concentrations of water soluble $\mathrm{Co}, \mathrm{Pb}$ and Cd by 48,34 and $20 \%$ respectively, compared with those of non-inoculated soils. Bacterial-assisted growth promotion and metal uptake in sunflower (Helianthus annuus) was evaluated in a pot experiment. In comparison with non-inoculated seedlings, the inoculation led to increase the growth of $H$. annuus by 24,18 and $16 \%$ respectively in $\mathrm{Co}, \mathrm{Pb}$ and $\mathrm{Cd}$ contaminated soils. Moreover, enhanced accumulation of $\mathrm{Co}, \mathrm{Pb}$ and $\mathrm{Cd}$ in the shoot and root systems was observed in inoculated plants, where metal translocation from root to the above-ground tissues was also found to be enhanced by the strain. Plant growth promotion and metal mobilizing potential of the strain suggest that the strain could effectively be employed in enhancing phytoextraction of $\mathrm{Co}, \mathrm{Pb}$ and $\mathrm{Cd}$ from contaminated soils.
\end{abstract}

Key words: Mobilization, Shewanella xiamenensis HM14, Bioaugmentation, Sunflower

Effect of inoculation with Shewanella xiamenensis HM14 on accumulation and translocation of $\mathrm{Co}$, Pb and $\mathrm{Cd}$ in Helianthus annuus.

\begin{tabular}{|c|c|c|c|c|c|}
\hline \multirow{2}{*}{ Metal } & \multirow{2}{*}{ Treatment } & \multicolumn{2}{|c|}{ Metal content (mg/kg dry weight) } & \multirow{2}{*}{$\begin{array}{l}\text { Bioconcentration } \\
\text { Factor }(\mathrm{BCF})^{\mathrm{a}}\end{array}$} & \multirow{2}{*}{$\begin{array}{l}\text { Translocation } \\
\text { Factor (TF) }\end{array}$} \\
\hline & & Shoot & Root & & \\
\hline \multirow{2}{*}{ Co } & control & $19.24( \pm 3.04)$ & $81.23( \pm 5.84)$ & 0.456 & 0.237 \\
\hline & with strain & $26.57( \pm 3.57)$ & $109.71( \pm 6.27)$ & 0.548 & 0.242 \\
\hline \multirow{2}{*}{$\mathrm{Pb}$} & control & $11.82( \pm 0.87)^{*}$ & $68.53( \pm 9.36)$ & 0.343 & 0.172 \\
\hline & with strain & $14.13( \pm 0.91)^{*}$ & $85.26( \pm 7.37)$ & 0.426 & 0.166 \\
\hline \multirow{2}{*}{$\mathrm{Cd}$} & control & $12.69( \pm 6.43)$ & $48.57( \pm 6.25)^{*}$ & 0.243 & 0.261 \\
\hline & with strain & $18.42( \pm 12.25)$ & $56.96( \pm 7.24)^{*}$ & 0.285 & 0.323 \\
\hline
\end{tabular}

${ }^{\mathrm{a}} \mathrm{BCF}=$ metal concentration ratio of plant roots to soil; ${ }^{\mathrm{b}} \mathrm{TF}=$ metal concentration ratio of plant shoots to roots.

Values are means $(n=3) \pm$ standard deviation. Within each column, the means indexed by * are not significantly different at $p>0.05$ between inoculated and non-inoculated plants according to Duncan's multiple range test.

*Corresponding author : Phone: +82428216733, Fax: +82428239241, E-mail: mhyoon@cnu.ac.kr

${ }^{\S}$ Acknowledgement: This study was supported by a grant from the research project of National Institute of Horticultural \& Herbal Science, Rural Development Administration, Republic of Korea. 


\section{Introduction}

Metal contamination of soils has become one of the most significant environmental problems today. Excessive metal uptake by crop plants from the contaminated agricultural lands can result in decreased crop yield due to the inhibition of plant metabolic processes (Singh and Aggarwal, 2006). Apart from the metals with unknown biological functions (Cd, $\mathrm{Cr}, \mathrm{Pb}, \mathrm{Co}, \mathrm{Ag}, \mathrm{Se}$, and $\mathrm{Hg}$ ), essential elements (Fe, Mn, $\mathrm{Zn}, \mathrm{Cu}, \mathrm{Mg}$, Mo, and $\mathrm{Ni}$ ) also keep accumulating in agricultural soils by means of wastewater irrigation, animal manures and sewage sludge application, use of fertilizer and agrochemicals (Thomas et al., 2012). In the toxicological point of view, the essential elements are also important, because, at higher concentrations they too can be toxic to plants as well as to dietary intake levels (Karavoltsos et al., 2002).

With the continuous addition of undesirable metals into the environment, remediation of contaminated soils receives increasing attention (Yeh and Pan, 2012). However, due to the fact that metals are not easily mineralized, remediation of the contaminated soils is always considered being a demanding exercise (Rajkumar et al., 2008). Depending on the resource availability, severity of the problem, nature of the metals and contaminated soil, different methods have been employed in restoring the contaminated lands (Arunakumara et al, 2013). In this context, systematic technologies such as bioremediation, physical/chemical remediation and integrated remediation are among the widely used techniques (Luo, 2009). However, the physical and chemical methods such as physical separation, acid leaching or electrochemical processes, are considered to be ineffective because of high cost, low efficiency, and destruction of soil structure and fertility (Jing et al., 2007). In contrast, phytoremediation, a method which uses plants to extract, sequester and detoxify pollutants has received considerable attention (Arunakumara, 2011). However, the wider application of the technology has been restricted due to the limitations such as low soil thickness that can be treated, low translocation rate of metals from roots to shoots, and the slowness of the treatment (Lebeau et al., 2008).

The amount of heavy metals uptake in plants varies with the mobility and the concentration of metals in soil (Chen et $a l ., 2010)$ and the interface between soil microbes and plant roots (rhizosphere) is displayed to have a great influence on the uptake of nutrients as well as on the decrease of metal toxicity (Ryan et al., 2009). Since soil microbes could alter the metal status of the soil (Fazal and Bano, 2010), exploitation of such microbes to reduce the metal toxicity to plants is worth investigating (Rajkumar and Freitas, 2008). In this context, some metal resistant bacterial strains were proved exceptional at enhancing the growth of the host plant through different mechanisms such as the production of plant growth promoting substances, nitrogen fixation and phosphate solubilization
(Hemambika et al., 2013). As reported by Rajkumar et al. (2008), heavy metal tolerance of the microbes may be attributed to one or several mechanisms including exclusion, active removal, biosorption, and precipitation or bioaccumulation of metals both in external and intracellular spaces. Therefore, microbes having remarkable metal tolerance and plant growthpromoting abilities could play a significant role in remediation of metal-contaminated soils, because bioaugmentation with such microbes could promote phytoextraction of metals (Prapagdee et al., 2013). In the present study, we isolated heavy metal resistance bacterial strains from metal-contaminated soils and the strain with the highest degree of metal resistance was employed in (i) assessing the potential of mobilization of Co, $\mathrm{Pb}$ and $\mathrm{Cd}$, and (ii) evaluating the effects of inoculation with the selected strain on plant growth and uptake of $\mathrm{Co}, \mathrm{Pb}$ and Cd by Helianthus annuus (sunflower).

\section{Materials and Methods}

Isolation of heavy metal alleviating bacteria Heavy metal contaminated soils were collected from the sediment tailing in abandoned mines of Boryeong area, South Korea. Aliquots of serially diluted soil samples were spread on Tryptic soy broth (TSB, $30 \mathrm{~g} \mathrm{~L}^{-1}$ ) agar media which was adjusted to $\mathrm{pH} 6.5 \pm 0.1$. The colonies on agar plate were purely isolated by repeated sub culturing at $30^{\circ} \mathrm{C}$ for 5 days. The preculture of each colonies was inoculated in $50 \mathrm{ml}$ TSB containing $0.2 \mathrm{~g}$ $-0.4 \mathrm{~g} \mathrm{~L}^{-1}$ of $\mathrm{CoCl}_{2} \cdot 6 \mathrm{H}_{2} \mathrm{O}, 2 \mathrm{PbCO}_{3} \cdot \mathrm{Pb}(\mathrm{OH})_{2}$, and $\mathrm{Cd}(\mathrm{NO})_{3}$ at $30^{\circ} \mathrm{C}$ for 7 days on a horizontal shaker at $150 \mathrm{rpm}$ and the culture filtrate was recovered after centrifugation at $8000 \times \mathrm{g}$ to isolate a metal alleviating bacteria. To determine aqueous elemental concentrations including $\mathrm{Co}, \mathrm{Pb}$, and $\mathrm{Cd}$, the culture filtrates were filtered through a $0.45 \mu \mathrm{m}$ nylon syringe filter (Watman, England) and acidified with $\mathrm{HNO}_{3}$ to minimize an interference by organic matters. The metal content of samples were analyzed using inductively-coupled plasma optical emission spectroscopy (ICP-AES. Optima 5300DA, PerkinElmer, USA) to estimate the metal concentration alleviated by each bacterium in medium and to select the bacterial strain showing the highest degree of metal alleviation.

Strain identification The partial sequencing of $16 \mathrm{~S}$ rRNA for the bacterial strain was done with the help of DNA sequencing service, SOLGENT, Daejeon, South Korea using universal primers, 27F (5'-AGAGTTTGATCCTGGCTCAG -3') and 1492R (5'-GGTTACCTTGTTACGACTT -3'). The online program BLAST was used in identifying the related sequences with known taxonomic information available at the databank of NCBI (http://www.ncbi.nlm.nih.gov/BLAST). A Phylogenetic tree was constructed using CLUSTAL X program (Thompson et al., 1997), which included sequence alignment by neighbor joining method (Saitou and Nei, 1987) and 
maximum parsimony using the MEGA4 program (Kumar et al., 2001). Grouping of sequences was based on confidence values obtained by bootstrap analysis of 1,000 replicates. Gaps were edited in the BioEdit program and evolutionary distances were calculated using Kimura two parameter model. Reference sequences were retrieved from GenBank under the accession numbers indicated in the trees.

Effect of heavy metals on bacterial growth TSB medium supplemented with heavy metals $(\mathrm{Co}, \mathrm{Pb}$ and $\mathrm{Cd})$ at the concentration of $200 \mathrm{mg} \mathrm{L}^{-1}$ was inoculated with bacterial suspension $\left(10^{6}\right.$ colony forming units $\left.\mathrm{ml}^{-1}\right)$ and incubated with continuous shaking at $30^{\circ} \mathrm{C}$ for 5 days. Optical density of culture supernatant was measured at definite time intervals using UV spectrophotometer at $660 \mathrm{~nm}$ to estimate the cell growth.

Assay of heavy metal contents in medium Bacterial culture having $10^{6}$ colony forming units $\mathrm{ml}^{-1}$ (2 days old) was inoculated in sterilized liquid TSB medium $(250 \mathrm{ml})$ supplemented with different heavy metals $(\mathrm{Co}, \mathrm{Pb}$ and $\mathrm{Cd})$ at the concentration of $200 \mathrm{mg} \mathrm{L}^{-1}$ and incubated with continuous shaking at $30^{\circ} \mathrm{C}$. Sterilized liquid TSB medium without supplemented with heavy metals was served as a control. A sample $(10 \mathrm{ml})$ of each culture and control were taken and centrifuged at 12000 $\times \mathrm{g}$ for $15 \mathrm{~min}$. The clear supernatant was used in determining the $\mathrm{pH}$ and amount of the metals remaining in the medium.

\section{Effect of bioagumentation on growth and metal uptake}

by $\boldsymbol{H}$. annuus A pot experiment was conducted under green house conditions at the College of Agriculture, Chungnam National University in April 2014. Several locations of soils collected from abandoned mines of Boryeong-gun as contaminated soil and a waste button mushroom compost in Buyeo-gun area, Chungchungnam-do, South Korea, were respectively mixed with the ratio of 1:1, air dried and sieved $(2 \mathrm{~mm})$. Sterilized forest soil (by steaming at $100^{\circ} \mathrm{C}$ for three consecutive days) was amended with aqueous solutions of different heavy metals $(\mathrm{Co}, \mathrm{Pb}$ and $\mathrm{Cd})$ to achieve the final concentrations of $200 \mathrm{mg} / \mathrm{kg}$ soil. They were then kept for 2 weeks in a greenhouse for metal stabilization and used in filling the plastic pots ( $25 \mathrm{~cm}$ diameter, $35 \mathrm{~cm}$ height). Seeds of Helianthus annuus were surface sterilized by immersing in alcohol (70\%) for $40 \mathrm{~s}, \mathrm{NaClO}(1.0 \%)$ for $15 \mathrm{~min}$ followed by rinsing several times with sterile distilled water. Seeds sown in germination trays containing sterilized non-contaminated soil were provided with $14 / 10$ light/dark regime and kept at $25^{\circ} \mathrm{C}$ for germination. Bacterial cultures grown under standard conditions for 2 days were harvested by centrifugation at $12000 \times \mathrm{g}$ at $15 \mathrm{~min}$. The cells were washed twice with sterile distilled water and resuspended in biological saline $(0.85 \% \mathrm{KCl})$ to be used in inoculation. Three weeks old seedlings were carefully uprooted from the germination bed and their roots were dipped in the bacterial culture $\left(10^{9}\right.$ colony forming units $\left.\mathrm{ml}^{-1}\right)$ for $2 \mathrm{~h}$. They were transplanted into the plastic pots (five plants/pot) containing $300 \mathrm{~g}$ of metal contaminated or non-contaminated soil and allowed to grow at $25^{\circ} \mathrm{C}$ and $14 / 10$ light/dark regime. The average $\mathrm{pH}$ of soil at the time of planting was recorded as 6.65. Three weeks later, the plants were carefully uprooted and cleaned the root surface thoroughly with distilled water. As growth parameters, fresh and dry biomass was measured and accumulation of metals in plant biomass was quantified as described by Freitas et al. (2004). Each treatment had three replicates.

Mobility of the metals in soil The impact of bacterial inoculation on the mobility of metals in soil was investigated under laboratory conditions with $50 \mathrm{ml}$ scaled polypropylene centrifuge tubes. The bacterial strain transferred into $100 \mathrm{ml}$ flasks containing TSB was cultured aerobically on a rotating shaker $(150 \mathrm{rpm})$ at $30^{\circ} \mathrm{C}$ until reaching the final concentration of $10^{8}$ colony forming units $\mathrm{ml}^{-1}$. The bacterial cells were then harvested by centrifugation at $10000 \times \mathrm{g}$ for $15 \mathrm{~min}$ and washed in phosphate buffer ( $\mathrm{pH}$ 7.0) twice. The bacterial pellet was washed in sterile water, re-centrifuged, and finally re-suspended in $5 \mathrm{ml}$ sterile water. Artificially contaminated soil $(5 \mathrm{~g})$ in the centrifuge tubes was inoculated with small aliquots (up to 5 $\mathrm{ml}$ ) of the final washed bacterial culture or $5 \mathrm{ml}$ extract of button mushroom compost. After taking the weight of the tubes, they were wrapped with brown paper and placed on an orbital shaker at $200 \mathrm{rpm}$ at $25^{\circ} \mathrm{C}$. At the end of the period of $10 \mathrm{~d}$, the weight of the tubes was recorded and $10 \mathrm{ml}$ of sterile water were added to each tube to extract the soil water soluble heavy metals. The extracts were centrifuged at $10000 \times \mathrm{g}$ for $10 \mathrm{~min}$ and filtered and the metal contents in the filtrate were determined using an ICP. Artificially contaminated soil without inoculation with the strain served as the control after centrifugation.

\section{Results}

Isolation and identification of heavy metal alleviating bacteria $A$ total of 16 bacterial strains with the potential ability to alleviate heavy metals were screened based on estimating the metal concentration alleviated by each bacterium in medium supplemented with 3 different heavy metals ( $\mathrm{Co}, \mathrm{Pb}$, and $\mathrm{Cd}$ ). A bacterial strain showing the highest degree of metal resistance and metal alleviation was finally selected for the study. According to 16S rRNA sequence analysis, the selected strain showed close proximity with Shewanella xiamenensis FJ589031. Phylogenetic tree (Fig. 1) shows the position of the isolated bacterium with respect to related species which is a facultative anaerobe with the ability to reduce cadmium as well as iron and manganese metabolically; that is, it can use iron and manganese as the terminal electron acceptor in the electron transport chain ( $\mathrm{Ng}$ et al. 2014). 


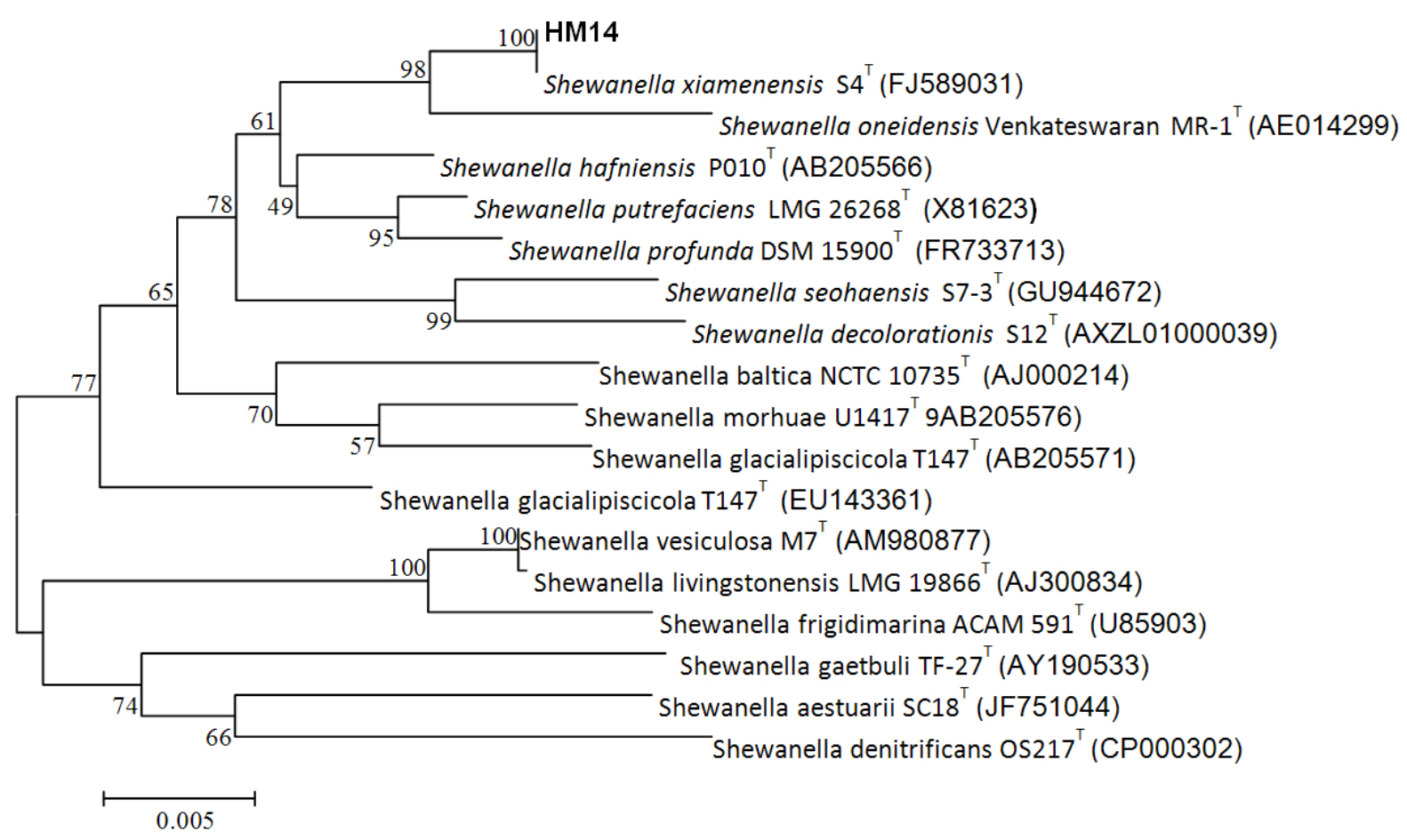

Fig. 1. Phylogenetic tree based on 16S rRNA gene sequences, showing the position of isolated metal solubilizing bacterial strain (HM14) with respect to related species. The scale bar indicates 0.002 substitutions per nucleotide position and accession numbers are given in parenthesis.

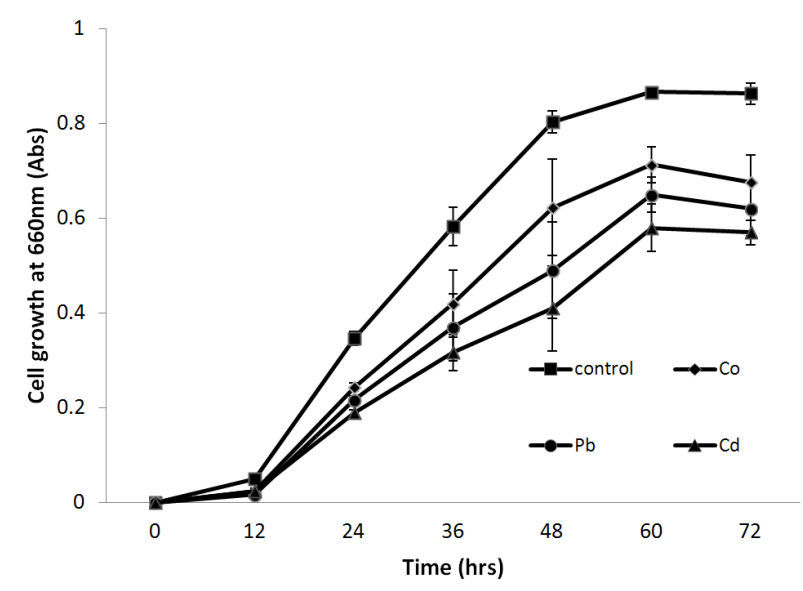

Fig. 2. Growth of Shewanella xiamenensis HM14 on sterilized liquid TSB medium supplemented with metals $(\mathrm{Co}, \mathrm{Pb}$ and Cd) at the concentrations of $200 \mathrm{mg} \mathrm{L}^{-1}$. Sterilized liquid TSB medium without supplemented with heavy metals was served as a control. Values are the means of three replicates. Error bars represent standard deviation.

Effect of heavy metals on bacterial growth The growth of the strain was monitored by measuring the optical density of culture supernatant supplemented with 3 different heavy metals $(\mathrm{Co}, \mathrm{Pb}$, and $\mathrm{Cd})$ at definite time intervals. Results show that the bacterium is slowly growing in liquid media with $200 \mathrm{mg} \mathrm{L}^{-1}$ of metals ( $\mathrm{Co}, \mathrm{Pb}$ and $\mathrm{Cd}$ ) and the growth reaches to maximal at $60 \mathrm{~h}$ after incubation. Although none of the metals was found to be highly toxic to the strain, slight

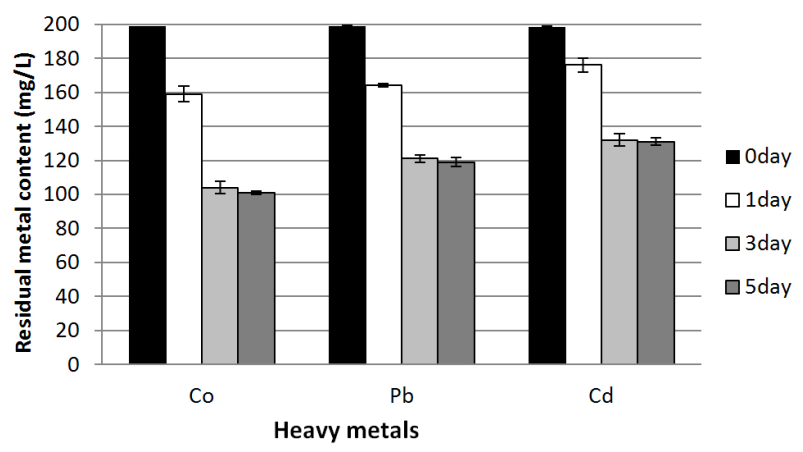

Fig. 3. Heavy metal alleviation by Shewanella xiamenensis HM14 on TSB medium supplemented with heavy metals (Co, $\mathrm{Pb}$ and $\mathrm{Cd}$ ) at the concentration of $200 \mathrm{mg} \mathrm{L}^{-1}$. Sterilized liquid TSB medium without supplemented with heavy metals was served as a control. Values are the means of three replicates. Emor bars represent standard deviation.

reductions in bacterial growth were observed in media supplemented media with $\mathrm{Pb}$ and $\mathrm{Cd}$, compared to the metal free culture medium (Fig. 2). These results indicate that $S$. xiamenensis HM14 is able to maintain the resistance under high heavy metal-growth conditions.

Alleviation of heavy metals Alleviation effect of heavy metals was estimated by measuring the amount of metals 
remaining in the TSB liquid medium inoculated with $S$. xiamenensis HM14. As depicted in Fig. 3, the strain was shown to be capable of reducing the amount of metal in the order of $\mathrm{Co}, \mathrm{Pb}$ and $\mathrm{Cd}$. Compared with the control, reductions of metals were 48,39 , and $34 \%$ for $\mathrm{Co}, \mathrm{Pb}$ and $\mathrm{Cd}$ at 3 day after incubation, respectively. This result represents that even growth of the strain somewhat resist at the presence of $\mathrm{m} \mathrm{L}^{-1}$ of metals, high density of cell growth caused metal solubilization in medium.

\section{Effect of bacterial strain on growth and metal uptake} by $\boldsymbol{H}$. annuus As showh in Table 1, inoculation with $S$. xiamenensis HM14 into sunflower (Helianthus annuus) pots resulted in increased fresh and dry biomass of $H$. annuus plants compared to non-inoculated plants. In case of the non-inoculated plants exposed by heavy metal stress, the growth of plant was inhibited in a significant level with $\mathrm{p}<0.05$. For instance, $\mathrm{Cd}$ toxicity caused 47 and $50 \%$ reductions in fresh and dry weight of the plant, respectively. Inoculation however led to increase in plant fresh and dry weight in the presence of heavy metals. The fresh and dry weight of the plants grown in $\mathrm{Cd}$ contaminated soils were respectively 18 and $15 \%$ higher than those of non-inoculated plants. Similarly, in $\mathrm{Pb}$ contaminated soil, the percent increments were recorded as 20 and 15\% respectively, and in Co contaminated soil, the corresponding figures were 20 and $28 \%$.

The amounts of $\mathrm{Co}, \mathrm{Pb}$ and $\mathrm{Cd}$ accumulated in the roots and shoots of $H$. annuus grown under inoculated and noninoculated conditions are given in Table 2. Inoculation with $S$. xiamenensis HM14 resulted in increased accumulation of metals both in the shoots and roots. The accumulations of Co, $\mathrm{Pb}$ and $\mathrm{Cd}$ in shoots were respectively 28,14 and $31 \%$ higher than those of non-inoculated plants. The corresponding accumulations for $\mathrm{Co}, \mathrm{Pb}$ and $\mathrm{Cd}$ in roots were 17, 20 and 15\% higher than those of non-inoculated plants. Regardless of inoculation or non-inoculation, the accumulation of metals in root system was found to be considerably higher than that of in shoots, which has been further confirmed by the low translocation factor (TF) for all the metals. However, TF of Co was somewhat higher than that of the other two metals. Similarly low bioconcentration factor (BCF) was also recorded from $\mathrm{Pb}$ and $\mathrm{Cd}$. However, the results showed a good agreement and demonstrated that inoculation of the bacterial strain led to increase both $\mathrm{TF}$ and $\mathrm{BCF}$ of the three metals distinctly.

Table 1. Effect of inoculation with Shewanella xiamenensis HM14 on shoot and not weight of Helianthus annuus.

\begin{tabular}{|c|c|c|c|c|c|}
\hline \multirow{2}{*}{ Metal } & \multirow{2}{*}{ Treatment } & \multicolumn{2}{|c|}{ Fresh weight (g/plant) } & \multicolumn{2}{|c|}{ Dry weight (g/plant) } \\
\hline & & Shoot & Root & Shoot & Root \\
\hline \multirow{2}{*}{$\begin{array}{l}\text { Metal free } \\
\text { soil }\end{array}$} & control & $1.74( \pm 0.043)$ & $0.109( \pm 0.012)$ & $0.089( \pm 0.005)$ & $0.036( \pm 0.004)$ \\
\hline & with strain & $1.91( \pm 0.035)$ & $0.127( \pm 0.008)$ & $0.102( \pm 0.004)$ & $0.054( \pm 0.007)$ \\
\hline \multirow{2}{*}{ Co } & control & $1.32( \pm 0.031)$ & $0.062( \pm 0.005)$ & $0.073( \pm 0.002)$ & $0.021( \pm 0.004)$ \\
\hline & with strain & $1.65( \pm 0.042)$ & $0.081( \pm 0.007)$ & $0.098( \pm 0.003)$ & $0.032( \pm 0.002)$ \\
\hline \multirow{2}{*}{$\mathrm{Pb}$} & control & $1.23( \pm 0.027)$ & $0.054( \pm 0.003)$ & $0.067( \pm 0.001)^{*}$ & $0.023( \pm 0.003)^{*}$ \\
\hline & with strain & $1.51( \pm 0.042)$ & $0.085( \pm 0.005)$ & $0.075( \pm 0.003)^{*}$ & $0.029( \pm 0.004)^{*}$ \\
\hline \multirow{2}{*}{$\mathrm{Cd}$} & control & $1.08( \pm 0.034)$ & $0.047( \pm 0.002)^{*}$ & $0.051( \pm 0.003) *$ & $0.015( \pm 0.002) *$ \\
\hline & with strain & $1.30( \pm 0.039)$ & $0.054( \pm 0.003)^{*}$ & $0.060( \pm 0.004) *$ & $0.018( \pm 0.003) *$ \\
\hline
\end{tabular}

Values are means $(n=3) \pm$ standard deviation. Within each column, the means indexed by $*$ are not significantly different at $p$

$>0.05$ between inoculated and non-inoculated plants according to Duncan's multiple range test.

Table 2. Effect of inoculation with Shewanella xiamenensis $\mathrm{HM14}$ on accumulation and translocation of $\mathrm{Co}$, $\mathrm{Pb}$ and $\mathrm{Cd}$ in Helianthus annuus.

\begin{tabular}{|c|c|c|c|c|c|}
\hline \multirow{2}{*}{ Metal } & \multirow{2}{*}{ Treatment } & \multicolumn{2}{|c|}{ Metal content (mg/kg dry weight) } & \multirow{2}{*}{$\begin{array}{c}\text { Bioconcentration } \\
\text { Factor }(\mathrm{BCF})^{\mathrm{a}}\end{array}$} & \multirow{2}{*}{$\begin{array}{l}\text { Translocation } \\
\text { Factor }(\mathrm{TF})^{\mathrm{b}}\end{array}$} \\
\hline & & Shoot & Root & & \\
\hline \multirow{2}{*}{$\mathrm{Co}$} & control & $19.24( \pm 3.04)$ & $81.23( \pm 5.84)$ & 0.456 & 0.237 \\
\hline & with strain & $26.57( \pm 3.57)$ & $109.71( \pm 6.27)$ & 0.548 & 0.242 \\
\hline \multirow{2}{*}{$\mathrm{Pb}$} & control & $11.82( \pm 0.87)^{*}$ & $68.53( \pm 9.36)$ & 0.343 & 0.172 \\
\hline & with strain & $14.13( \pm 0.91)^{*}$ & $85.26( \pm 7.37)$ & 0.426 & 0.166 \\
\hline \multirow{2}{*}{$\mathrm{Cd}$} & control & $12.69( \pm 6.43)$ & $48.57( \pm 6.25)^{*}$ & 0.243 & 0.261 \\
\hline & with strain & $18.42( \pm 12.25)$ & $56.96( \pm 7.24)^{*}$ & 0.285 & 0.323 \\
\hline
\end{tabular}

${ }^{\mathrm{a}} \mathrm{BCF}=$ metal concentration ratio of plant roots to soil; ${ }^{\mathrm{b}} \mathrm{TF}=$ metal concentration ratio of plant shoots to roots.

Values are means $(n=3) \pm$ standard deviation. Within each column, the means indexed by $*$ are not significantly different at $p$ $>0.05$ between inoculated and non-inoculated plants according to Duncan's multiple range test. 


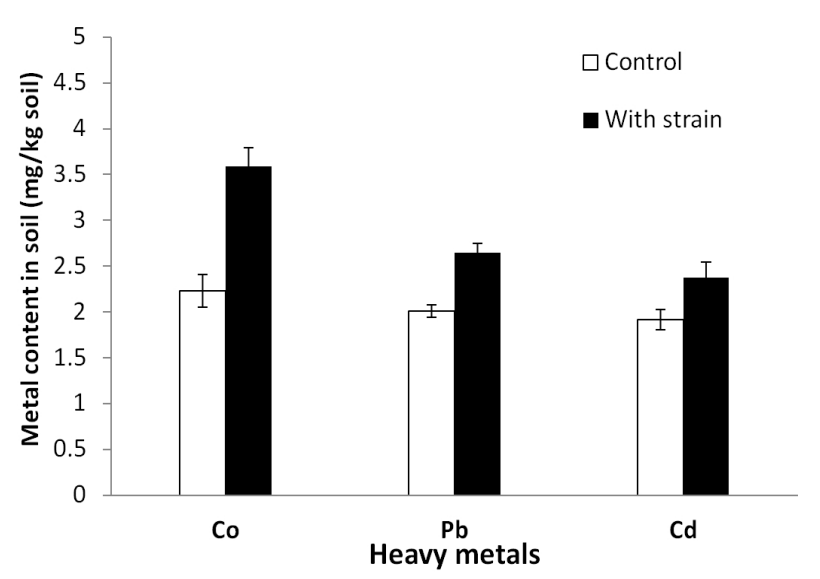

Fig. 4. Effect on mobilization of $\mathrm{Co}, \mathrm{Pb}$ and $\mathrm{Cd}$ in soil by inoculation with Shewanella xiamenensis HM14. Soil without inoculation the strain served as the control. Values are the means of three replicates. Emor bars represent standard deviation.

Mobility of the metals in soil To investigate the impact of bacterial inoculation on the mobility of metals in soil, metal mobilization potential of the strain was assessed in a batch experiment with artificially contaminated soil. As given in Fig. 4, inoculation of the strain could increase the contents of water soluble metals from the soil extract, representing that heavy metals could be solubilized by microorganism inoculation. The mobilization of $\mathrm{Co}, \mathrm{Pb}$ and $\mathrm{Cd}$ was respectively 38, 34 and $20 \%$ higher than those of the control soil.

\section{Discussion}

Growth response of the present strain under metal contamination conditions is in line with Rajkumar et al. (2008) and Prapagdee et al. (2013), who observed $\mathrm{Zn}, \mathrm{Cu}$ and $\mathrm{Ni}$ resistance in Bacillus weihenstephanensis and $\mathrm{Cd}$ resistance in Klebsiella sp. BAM1. Generally microorganisms isolated from heavy metals contaminated soils possess the ability to withstand against multiple pollutants as they have adapted to such environments (Pal et al., 2005; Abou-Shanab et al., 2007)

The effectiveness of the strain as a plant growth-promoter was assessed with Helianthus annuus, a species known to have an ability to accumulate biomass rapidly and take up substantial amounts of metals (Turgut et al., 2004; Prapagdee et al., 2013). As reported by Ouzounidou et al. (2005) and El-Tayeb et al. (2006), accumulation of plant biomass could be affected by excessive concentrations of heavy metals, which exert adverse impacts on growth and function of root system resulting in poor uptake of water and nutrients. As reported by Jiang et al. (2008), inoculation with Burkholderia sp. J62 led to increase shoot and root dry weights of corn and tomato plants. Inoculation with Pseudomonas fluorescens PsIA12 resulted in enhanced growth of Zea mays and its uptake of N, P and K (Egamberdiyeva et al., 2002). The content of $\mathrm{P}, \mathrm{K}, \mathrm{S}$ and $\mathrm{Ca}$ was reported to be increased by the inoculation of rhizobacteria in barley plant grown in metal contaminated soil (Belimov et al., 2004). According to them, inoculation with rhizobacteria resulted in $42 \%$ increase in growth of the barley plant compared to the control. Based on the results, they further stated that nutrients play an important role in the detoxification of heavy metals. Their findings were in line with Lebeau et al. (2008), who reported that rhizobacteria could have strong impacts on the nutritional status and the plant resistance to heavy metals. Most recently, Prapagdee $e t$ al. (2013) reported that growth of H. annuus could be enhanced by the inoculation of Micrococcus sp. MU1 and Klebsiella sp. BAM1 under Cd contaminated conditions. Belimov et al. (2001) also observed bacterial-assisted growth enhancement in Brassica napus grown in a soil contaminated with $\mathrm{Cd}$. The plant growth-promoting potential of the present strain could be attributed at least partly to the phosphate solubilization ability of the strain under metal stress conditions. In this regards, Rajkumar et al. (2005) also reported that phosphate solubilization ability of Pseudomonas sp. could be contributed to the growth enhancement of the inoculated plants. Inoculation of phosphate solubilizing Bacillus subtilis SJ-101 resulted in higher shoot and root length and biomass with or without $\mathrm{Ni}$ (Zaidi et al., 2006). Bacteria is reported to promote the growth of plants (i) indirectly through producing antibiotics to inhibit soil pathogens, and (ii) directly through increasing nutrient and water uptake and thereby the plant biomass (Belimov et al., 2004). Through the production of siderophores, specific enzymes, and organic acids involved in phosphorus solubilization, and fixation of atmospheric $\mathrm{N}_{2}$, bacteria could assist plants to withstand against metal toxicity (Kloepper, 2003). In this regards, Borgmann (2000) reported that Kluyvera ascorbata SUD165 protected Brassica juncea and Brassica campestris against $\mathrm{Ni}, \mathrm{Pb}$ and $\mathrm{Zn}$ toxicity through the production of enzyme ACC deaminase. Plant growth promoting rhizobacteria was reported to enhance root elongation of Brassica napus by stimulating IAA synthesis (Sheng and Xia, 2006). In Brassica juncea, root elongation was reported to be enhanced by non-identified rhizobacteria (Belimov et al., 2005), Variovorax paradoxus 5C-2 (Belimov et $a l ., 2005)$ and root dry weight was increased by rhizobacteria (Sheng and Xia, 2006).

Regardless of inoculation or non-inoculation, the accumulation of metals in root systems was found to be considerably higher than that of in shoots. This could primarily be attributed to the poor translocation of heavy metals from roots to shoots (Rajkumar et al., 2006). However, as shown in Table 2, translocation factor of the each metal was increased with the inoculation of the strain, which was of enormous practical significance. Furthermore, metal accumulations in both shoots and roots were found to be higher in inoculated plants 
than those of non-inoculated plants. Similar observations were made by Rajkumar et al. (2008) for $\mathrm{Zn}$ accumulation in H. annuus inoculated with Bacillus weihenstephanensis. However, according to Wani et al. (2007), inoculation of Bradyrhizobium sp. on surface sterilized seeds of Vigna radiate reduced the concentration of $\mathrm{Ni}$ in roots, shoots and grains by 15,19 and $22 \%$, respectively, compared with non-inoculated plants.

The inter-relationships among soil $\mathrm{pH}$, solubility and speciation of metals have been intensively investigated (Gadd, 2004). Bacteria such as Azotobacter chroococcum (N-fixing bacteria), Bacillus megaterium (P-solubilizer) and Bacillus mucilaginosus (K-solubilizer) (Wu et al., 2006) and Bacillus sp. RJ16 (Sheng and Xia, 2006) were reported to decrease the $\mathrm{pH}$, enhancing the bioavailability of $\mathrm{Cd}, \mathrm{Pb}$ and $\mathrm{Zn}$ (Chen et al., 2005). As stated by Zaidi et al. (2006), reduction in $\mathrm{pH}$ from 7.5 to 4.8 with the inoculation of phosphate solubilizing Bacillus subtilis SJ-101 possibly created favourable conditions for the solubilization of metals and their subsequent uptake by the plants. The increased accumulation of metals in the presence of bacterial strain might be due to the increased uptake of metals under acidic soil conditions created by the phosphate solubilization (Rajkumar et al., 2008). Inoculation of Cd-resistant bacterial strains to Brassica napus to a metal contaminated soil significantly increased the plant uptake of $\mathrm{Cd}$ when compared with the non-inoculated controls, as a result of $\mathrm{pH}$ reduction (Sheng and Xia, 2006). However, on the contrary, Glomus caledonium (Chen et al., 2004) and Glomus mosseae (Citterio et al., 2005) were reported to have no effect on the speciation of $\mathrm{Cd}$ and $\mathrm{Zn}$, and $\mathrm{Cr}$ and $\mathrm{Ni}$, thus no effect of bioaugmentation by these arbuscular mycorrhizal (AM) fungi on the rate of phytoextraction has been observed, which could be attributed to whether strong symbiotic relationships between AM fungi and host plants.

The present findings of metal mobilization are in agreement with Wu et al. (2006) and Prapagdee et al. (2012) who also reported bacteria-assisted increase in heavy metal mobilization. Generally, the low amount of metals extracted by plants from a soil is attributed mainly to the low availability of metals. As reported by several authors, the available metal content in a soil is less than $1 \%$ of the total metal content (Whiting et al., 2001; Braud et al., 2006). Metal availability is influenced by the nature of the metal and soil characteristics such as $\mathrm{pH}$, CEC and organic matter (Kayser et al., 2001; Lebeau et al., 2008). Bioaugmentation could enhance metal bioavailability by increasing the concentration of the available fractions. As revealed by the present results, the release of heavy metals from the non-soluble phases to soluble phases could be facilitated by the bacterial strain. Therefore, increased accumulation of metals, in particular Co in both the shoots and roots of $H$. annuus could be attributed to the higher water soluble metal contents in soil inoculated with bacterial strain. As reported by the results of previous studies, $H$. annuus is capable of accumulating high amounts of $\mathrm{Pb}, \mathrm{Cd}, \mathrm{Cu}, \mathrm{Zn}$ and $\mathrm{Co}$, in both the shoots and the roots (Boonyapookana et al., 2005; Marchiol et al., 2007). According to Braud et al. (2006), inoculation of Pseudomonas aeruginosa and Pseudomonas fluorescens has resulted in $113 \%$ increment of $\mathrm{Pb}$ content in the exchangeable fraction of the soil. However, the $\mathrm{Pb}$ concentration bound to free $\mathrm{Mn}$ oxides, organic matter and in the residual fraction remained stable. Abou-Shanab et al. (2006) observed an increase of extractable Ni with Microbacterium arabinogalactanolyticum by a factor up to 15 . As reported by Baum et al. (2006), the concentrations in $\mathrm{NH}_{4} \mathrm{NO}_{3}$-extractable $\mathrm{Cd}, \mathrm{Cu}, \mathrm{Pb}$ and $\mathrm{Zn}$ in a soil bioaugmented with ectomycorrhizal fungus Paxillus involutus, were 1.22-, 1.11-, 1.33- and 1.33-fold higher than those of non-bioaugmented soil, depending on the soil composition. However, comparing and contrasting of the results of bioaugmentation studies are hard to perform, because the estimation of bioavailable fraction of metals has been done under different conditions with different extractants such as water (Di Gregorio et al., 2006; Wu et al., 2006), $\mathrm{MgCl}_{2}$ (Braud et al., 2006), $\mathrm{NH}_{4} \mathrm{NO}_{3}$ (Baum et al., 2006), $\mathrm{NH}_{4} \mathrm{O}-\mathrm{Ac}$ (Wu et al., 2006), DTPA (Di Gregorio et al., 2006; Wu et al., 2006), $\mathrm{KNO}_{3}$ (Di Gregorio et al., 2006) and $\mathrm{HCl}$ (Wang et al., 2007).

\section{Conclusion}

The strain, Shewanella xiamenensis HM14 was found to be capable of solubilizing metals ( $\mathrm{Co}, \mathrm{Pb}$ and $\mathrm{Cd}$ ). Metal mobilization potential of the strain showed that inoculation could increase the concentrations of water soluble $\mathrm{Co}, \mathrm{Pb}$ and $\mathrm{Cd}$ than those of non-inoculated soils. Inoculation with the strain also resulted in increased shoot and root biomass and enhanced accumulation of $\mathrm{Co}, \mathrm{Pb}$ and $\mathrm{Cd}$ in Helianthus annuus plants. The strain was found to be capable of promoting metal translocation from the roots to the shoots of $H$. annuus. Therefore, Shewanella xiamenensis HM14 could be identified as an effective promoter of phytoextraction of $\mathrm{Co}, \mathrm{Pb}$ and $\mathrm{Cd}$ from metal-contaminated soils.

\section{References}

Abou-Shanab, R.A.I., J.S. Angle, and R.L. Chaney. 2006. Bacterial inoculants affecting nickel uptake by Alyssum murale from low, moderate and high Ni soils. Soil Biol. Biochem. 38:2882-2889.

Abou-Shanab, R.A.I., P. van Berkum, and J.S. Angle. 2007. Heavy metal resistance and genotypic analysis of metal resistance genes in gram-positive and gram-negative bacteria present in Ni-rich serpentine soil and in the rhizosphere of Alyssum murale. Chemosphere. 68:360-367.

Arunakumara, K.K.I.U. 2011. Use of Crop Plants for Removal of Toxic Metals, pp. 439-457. In Khan MS, Zaidi A, Goel R, and 
Mussarrat J. (eds.),Bio-management of Metal Contaminated Soils- 2011. Springer, Springer Science + Business Media B.V.

Arunakumara, K.K.I.U., B.C. Walpola, and M.H. Yoon. 2013. Banana peel: A green solution for metal removal from contaminated waters. Korean J. Environ. Agric. 32:108-116.

Arunakumara, K.K.I.U., B.C. Walpola, and M.H. Yoon. 2013. Agricultural methods for toxicity alleviation in metal contaminated soils. Korean J. Soil Sci. Fert. 46:73-80.

Baum, C., K. Hrynkiewicz, P. Leinweber, and R. Meissner. 2006. Heavy-metal mobilization and uptake by mycorrhizal and nonmycorrhizal willows (Salix dasyclados). J. Plant Nutr. Soil Sci. 169:516-522.

Belimov, A.A., N. Hontzeas, V.I. Safronova, S.V. Demchinskaya, G. Piluzza, S. Bullitta, and B.R. Glick. 2005. Cadmium-tolerant plant growth-promoting bacteria associated with the roots of Indian mustard (Brassica juncea L. Czern.). Soil Biol. Biochem. 37:241-250

Belimov, A.A., A.M. Kunakova, V.I. Safronova, V.V. Stepanok, L.Y. Yudkin, Y.V. Alekseev, and A.P. Kozhemyakov. 2004. Employment of rhizobacteria for the inoculation of barley plants cultivated in soil contaminated with lead and cadmium. Microbiology. 73:99-106.

Belimov, A.A., V.I. Safronova, T.A. Sergeyeva, T.N. Egorova, V.A. Matveyeva, V.E. Tsyganov, A.Y. Borisov, and I.A. Tikhonovich. 2001. Characterisation of plant growth-promoting rhizobacteria isolated from polluted soils and containing 1-aminocyclopropane-1-carboxylate deaminase. Can. J. Microbiol. 47:642-652.

Boonyapookana, B., P. Parkpian, S. Techapinyawat, R.D. DeLaun, and A. Jugsujinda. 2005. Phytoaccumulation of lead by sunflower (Helianthus annuus), tobacco (Nicotiana tabacum), and vetiver (Vetiveria zizanioides). J. Environ. Sci. Health, Part A. 40:117-137.

Borgmann, U. 2000. Methods for assessing the toxicological significance of metals in aquatic ecosystems: bio-accumulationtoxicity relationships, water concentrations and sediment spiking approaches. Aquat. Ecosyst. Health. 3:277-289.

Braud, A., K. Jezequel, E. Vieille, A. Tritter, and T. Lebeau. 2006. Changes in extractability of $\mathrm{Cr}$ and $\mathrm{Pb}$ in a polycontaminated soil after bioaugmentation with microbial producers of biosurfactants, organic acids and siderophores. Water Air Soil Poll. 6:261-279.

Cervantes, C., J. Chavez, N.A. Cardova, P. de la Mora, and J.A. Velasco. 1986. Resistance to metal by Pseudomonas aeruginosa clinical isolates. Microbios. 48:159-163.

Chen, B., H. Shen, X. Li, G. Feng, and P. Christie. 2004. Effects of EDTA application and arbuscular mycorrhizal colonization on growth and zinc uptake by maize (Zea mays L.) in soil experimentally contaminated with zinc. Plant Soil. 261:219-229.

Chen, Y.E., S. Yuan, Y.Q. Su, and L. Wang. 2010. Comparison of heavy metal accumulation capacity of some indigenous mosses in Southwest China cities: a case study in Chengdu city. Plant Soil Environ. 56:60-66.

Chen, Y.X., Y.P. Wang, Q. Lin, and Y.M. Luo. 2005. Effect of copper-tolerant rhizosphere bacteria on mobility of copper in soil and copper accumulation by Elsholtzia splendens. Environ. Int. 31:861-866.

Citterio, S., N. Prato, P. Fumagalli, R. Aina, N. Massa, A. Santagostino, S. Sgorbati, and G. Berta. 2005. The arbuscular mycorrhizal fungus Glomus mosseae induces growth and metal accumulation changes in Cannabis sativa L. Chemosphere. 59:21-29.

Di Gregorio, S., M. Barbafieri, S. Lampis, A.M. Sanangelantoni, E. Tassi, and G. Vallini. 2006. Combined application of Triton X-100 and Sinorhizobium sp. Pb002 inoculum for the improvement of lead phytoextraction by Brassica juncea in EDTA amended soil. Chemosphere. 63:293-299.

Egamberdiyeva, D., D. Juraeva, L. Gafurova, and G. Ho“flich. 2002. Promotion of plant growth of maize by plant growth promoting bacteria in different temperature and soils. In van Santen, E. (ed.), Making Conservation Tillage Conventional: Building a Future on 25 Years of Research. Proceedings of $25^{\text {th }}$ Annual Southern Conservation Tillage Conference for Sustainable Agriculture. Auburn, AL 24-26 June 2002. Special Report No. 1. Alabama Agricultural Experiment Station and Auburn University, AL 36849, USA.

El-Tayeb, M.A., A.E. El-Enany, and N.L. Ahmed. 2006. Salicylic acid-induced adaptive response to copper stress in sunflower (Helianthus annuus L.). Plant Growth Regul. 50:191-199.

Fazal, H. and A. Bano. 2010. The effect of diazotrophs (rhizobium and azatobactor) on growth and biomass of maize in lead $(\mathrm{Pb})$ polluted soil, and accumulation of the lead in different parts of plant. Pak. J. Bot. 42:4363-4370.

Freitas, H., M.N.V. Prasad, and J. Pratas. 2004. Analysis of serpentinophytes from north-east of Portugal for trace metal accumulation-relevance to the management of mine environment. Chemosphere. 54:1625-1642.

Gadd, G.M. 2004. Microbial influence on metal mobility and application for bioremediation. Geoderma. 122:109-119.

Hemambika, B., V. Balasubramanian, V.R. Kannan, and R.A. James. 2013. Screening of chromium-resistant bacteria for plant growth-promoting activities. Soil Sediment Contam. 22:717-736.

Jiang, C.Y., X.F. Sheng, M. Qian, and Q.Y. Wang. 2008. Isolation and characterization of a heavy metal-resistant Burkholderia sp. from heavy metal-contaminated paddy field soil and its potential in promoting plant growth and heavy metal accumulation in metal-polluted soil. Chemosphere. 72:157-164.

Jing, Y.D., Z.L. He, and X.E. Yang. 2007. Role of soil rhizobacteria in phytoremediation of heavy metal contaminated soils. J. Zhejiang Univ. SC B. 8:192-207.

Karavoltsos, S., A. Sakellari, M. Dimopoulos, M. Dassenakis, 
and M. Scoullos. 2002. Cadmium content in foodstuffs from the Greek market. Food Addit. Contam. 19:954-962.

Kayser, G., T. Korckritz, and B. Markert. 2001. Bioleaching for the decontamination of heavy metals. Wasser. Boden. 53:54-58.

Kloepper, J.W. 2003. A review of mechanisms for plant growth promotion by PGPR, pp. 81-92. In Sixth International PGPR Workshop, Calicut, India.

Kumar, S., K. Tamura, I.B. Jakobsen, and M. Nei. 2001. MEGA2: molecular evolutionary genetics analysis software. Bioinformatics. 17:1244-1245.

Lebeau, T., A. Braud, and K. Je'ze'quel. 2008. Performance of bioaugmentation-assisted phytoextraction applied to metal contaminated soils: A review, Environ. Pollut. 153:497-522.

Luo, L., Y. Ma, S. Zhang, D. Wei, and Y.G. Zhu. 2009. An inventory of trace element inputs to agricultural soils in China. J. Environ. Manage. 90:2524-2530.

Marchiol, L., G. Fellet, D. Perosa, and G. Zerbi. 2007. Removal of trace metals by Sorghum bicolor and Helianthus annuus in a site polluted by industrial wastes: a field experience. Plant Physiol. Biochem. 45:379-387.

Nautiyal CS. 1999. An efficient microbiological growth medium for screening of phosphate solubilizing microorganisms. FEMS Microbiol. Lett. 170:265-270.

Ng, I. S., Chen, T., and Lin, R. 2014. Decolorization of textile azo dye and Congo red by an isolated strain of the dissimilatory manganese-reducing bacterium Shewanella xiamenensis $\mathrm{BC} 01$. Appl. Microbiol. Biotechnol. 98:2297-2308.

Ouzounidou, G. and I. Ilias. 2005. Hormone-induced protection of sunflower photosynthetic apparatus against copper toxicity. Bio. Plantarum.49:223-228.

Pal, A., S. Dutta, P.K. Mukherjee, and A.K. Paul. 2005. Occurrence of heavy metal resistance in microflora from serpentine soil of Andaman. J. Basic Microbiol. 45:207-218.

Prapagdee, B., N. Chumphonwong, and N. Khonsue. 2012. Influence of cadmium resistant bacteria on promoting plant root elongation and increasing cadmium mobilization in contaminated soil. Fresenius Environmental Bulletin. 21:1186-1191.

Prapagdee, B., M. Chanprasert, and S. Mongkolsuk. 2013. Bioaugmentation with cadmium-resistant plant growth-promoting rhizobacteria to assist cadmium phytoextraction by Helianthus annuus. Chemosphere. 92:659-666.

Rajkumar, M., M. Ying, and H. Freitas. 2008. Characterization of metal-resistant plant-growth promoting Bacillus weihenstephanensis isolated from serpentine soil in Portugal. J. basic microbial. 48:500-508.

Ryan, P.R., Y. Dessaux, L.S. Thomashow, and D.M. Weller.
2009. Rhizosphere engineering and management for sustainable agriculture. Plant Soil. 321:363-383.

Saitou, N., and M. Nei. 1987. The neighbor-joining method: a new method for reconstructing phylogenetic trees. Mol. Biol. Evol. 4:406-425.

Sheng X.F., and J.J. Xia. 2006. Improvement of rape (Brassica napus) plant growth and cadmium uptake by cadmiumresistant bacteria. Chemosphere. 64:1036 - 1042

Singh, S., and P.K. Aggarwal. 2006. Effect of heavy metals on biomass and yield of different crop species. Indian J. Agric. Sci. 76:688-691.

Thomas, E.Y., J.A.I., Omueti, and O. Ogundayomi. 2012. The effect of phosphate fertilizer on heavy metal in soils and Amaranthus Caudatu. Agric. Biol. J. N. Am. 3:145-149.

Thompson, J. D., T. J. Gibson, F. Plewniak, F. Jeanmougin, and D. G. Higgins. 1997. The Clustal X windows interface: flexible strategies for multiple sequence alignment aided by quality analysis tools. Nucleic Acids Res. 24:4876-4882.

Turgut C., M. Katie Pepe, and T.J. Cutright. 2004. The effect of EDTA and citric acid on phytoremediation of $\mathrm{Cd}, \mathrm{Cr}$, and $\mathrm{Ni}$ from soil using Helianthus annuus. Environ. Pollut. 131:147-154.

Ryan, P.R., Y. Dessaux, L.S. Thomashow, and D.M. Weller. 2009. Rhizosphere engineering and management for sustainable agriculture. Plant Soil. 321: 363-383.

Wani, P.A., M.S. Khan, and Z. Almas. 2007. Synergistic effects of the inoculation with nitrogen-fixing and phosphate-solubilizing rhizobacteria on the performance of field-grown chickpea. J. Plant Nutr. Soil Sci. 170:283-287.

Wang, Y.P., J. Y. Shi, and Q. Lin. 2007. Heavy metal availability and impact on activity of soil microorganisms along a $\mathrm{Cu} / \mathrm{Zn}$ contamination gradient. J. Environ. Sciences. 19:848-853.

Whiting S. N., M. P. de Souza, and N. Terry. 2001. Rhizosphere Bacteria Mobilize Zn for Hyperaccumulation by Thlaspicaerulescens. Environ. Science \& Technol. 35:3144-3150.

Wu S.C., K.C. Cheung, and Y.M. Luo. 2006. Effects of inoculation of plant growth-promoting rhizobacteria on metal uptake by Brassica juncea. Environ. Pollut.140:124-135.

Yeh, T.Y., and C.T. Pan. 2012. Effect of chelating agents on copper, zinc, and lead uptake by sunflower, Chinese cabbage, cattail, and reed for different organic contents of soils. J. Environ. Anal. Toxicol. 2: doi:10.4172/2161-0525. 1000145.

Zaidi S., S. Usmani, and B.R. Singh. 2006. Significance of Bacillus subtilis strain SJ-101 as a bioinoculant for concurrent plant growth promotion and nickel accumulation in Brassica juncea. Chemosphere.64:991-997. 